Fecha de recepción: febrero 2013 Fecha de aceptación: julio 2013 Versión final: diciembre 2014

\section{La intermedialidad en el centro de las propuestas escénicas de Diego Casado Rubio}

Ezequiel Lozano *

\begin{abstract}
Resumen: Entendiendo la intermedialidad como la integración de los conceptos estéticos provenientes de medios de comunicación diferentes en un contexto novedoso -en este caso una puesta en escena-, la pretensión de este escrito es pensar las propuestas artísticas del director Diego Casado Rubio desde dicha noción. Este multifacético madrileño, que además de director cinematográfico y teatral se dedica al diseño gráfico para teatro, al desarrollo de proyectos de video y a la escritura, se radicó en Buenos Aires en 2005 desarrollando una vasta producción teatral en diferentes roles. Haciendo referencia a sus demás labores este artículo se centrará en el análisis de las dos obras teatrales escritas y dirigidas por Casado Rubio: Es inevitable y Se alquila, con una condición.
\end{abstract}

Palabras clave: cine - dramaturgia - intermedialidad - queer - tecnología.

[Resúmenes en inglés y portugués en las páginas 60-61]

${ }^{(*)}$ Licenciado en Artes por la Facultad de Filosofía y Letras de la Universidad de Buenos Aires. Actualmente es doctorando en esa misma facultad y becario del CONICET. Además, obtuvo el título terciario de Profesor de Filosofía y Ciencias de la Educación. Cuenta con experiencia docente en los niveles de enseñanza terciaria, media y primaria. En la actualidad se desempeña como profesor auxiliar de la cátedra de "Análisis y Crítica del Hecho Teatral" en la Facultad de Filosofía y Letras de la Universidad de Buenos Aires. Además es autor, director y actor teatral.

Escena 6: En la cocina. En el escenario podemos ver un comedor diario representado por una mesa y un par de sillas tras la abertura de una pared interna. Cerca de este espacio una habitación con una cama donde está acostado un muchacho. En dicho comedor se sirve la comida. Las comensales se sientan a compartir ese pan. Escena repetida en sucesivas obras -trasvasada por incontables poéticas- aparece, aquí, con un nuevo matiz. En proyección, contigua a la escenografía que representa el comedor, una cámara nos muestra con detalles la cocina de esa misma casa. Las acciones de estos personajes que arrancan en la escena representada del comedor pasan del espacio teatral de la representación hacia el espacio audiovisual (espacio virtual que amplía y conforma, sin dilaciones de tiempo, la misma situación que estamos viendo). El autor lo señala de esta forma en el texto dra- 
mático "En este momento hay tres escenas en simultáneo: en la habitación Amador trata de dormir, en la cocina Lucía come sopa, en la pantalla Ramona agarra el vino" (Casado Rubio). De igual manera detalla, en su texto escrito, cada uno de los videos que se entrelazan en la escena de la cocina.

La escena anterior corresponde a Se alquila con una condición, la segunda obra teatral escrita y dirigida por Diego Casado Rubio. Es una misma y única escena teatral aprendiendo a hablar un lenguaje cinematográfico. Los espacios contiguos representados en el escenario se despliegan ante el público y no quedan ya ocultos tras bambalinas, y su modo de desplegarse se vincula con su capacidad para utilizar soportes diferentes. Porque de esto se trata hablar de la producción de Diego Casado Rubio. Se trata de entender el discurrir audiovisual de la dramaturgia, las potencias plásticas de la representación teatral, el cine hecho cuerpo en convivio.

Entendiendo a la intermedialidad como la integración de los conceptos estéticos provenientes de medios de comunicación diferentes en un contexto novedoso -en este caso una puesta en escena-, la pretensión de este escrito es pensar las propuestas artísticas del director Diego Casado Rubio desde dicha noción. María Fernanda Pinta caracteriza de este modo el concepto señalado:

Construido sobre la base de la noción de intertextualidad, el término intermedialidad alude a los intercambios entre los medios de comunicación y su impacto en la representación teatral. En este sentido, los medios de comunicación y el teatro, aunque heterogéneos en sus soportes, materia expresiva, circuitos de producción y recepción son puestos en relación con el fin de explorar las posibilidades comunicacionales y expresivas del teatro a la luz de los desafíos que le ofrecen los medios masivos de comunicación y del entretenimiento en la sociedad del espectáculo. (Pinta, 2010, p. 1).

El tránsito escénico por soportes heterogéneos es consecuente, a su vez, con el trayecto del desarrollo profesional de Casado Rubio. Este multifacético madrileño se radicó en Buenos Aires en 2005 desarrollando una vasta producción teatral en diferentes roles. Además de trabajar como director cinematográfico y teatral se dedicó al diseño gráfico para teatro, al desarrollo de proyectos de video y a la escritura. Antes de llegar a Argentina obtuvo su licenciatura en Ciencias de la Información y Comunicación. En España pudo trabajar en televisión y en radio pero su gran pasión fue siempre el cine por lo cual se formó en el Instituto de Cine de Madrid. A su vez, La Factoría del Guión fue su escuela y Pedro Loeb (argentino residente en España) uno de sus maestros. Si bien siempre supo que quería ser un realizador audiovisual el camino que eligió para adquirir oficio fue el de formarse, de modo sólido, como guionista. Este dato no es menor porque también muestra que su ingreso al cine -a la dirección de cine nos referimos- fue desde una dinámica personal. Así, en una entrevista que compartimos ${ }^{1}$, nos ratificó que se formó como guionista de cine, con el objetivo de dirigir: 
No quise entrar directamente por dirección ya que entendía que era más copado ese ingreso. Aparte yo escribía, siempre me gustó escribir, y sentía que eso lo tenía que canalizar por algún lado. Y el cine tiene una estructura y un formato muy concreto porque cuesta pasta. O sea desde ese lugar te tenés que ceñir a eso. Pero mi objetivo era dirigir. Y, cuando estaba estudiando cine no pensé nunca la posibilidad de hacer teatro. Llego a Buenos Aires y se me abre la cabeza (Casado Rubio en Lozano, 2011).

Esa mixtura de soportes en escena también es mixtura de culturas que flota en su modo de hablar madrileño y porteño a la vez. Cruce cultural que señalamos porque también se hace presente en los tópicos de las dos obras teatrales de este director (en ambas aparecen personajes que viven o vivieron en España y ahora en Argentina).

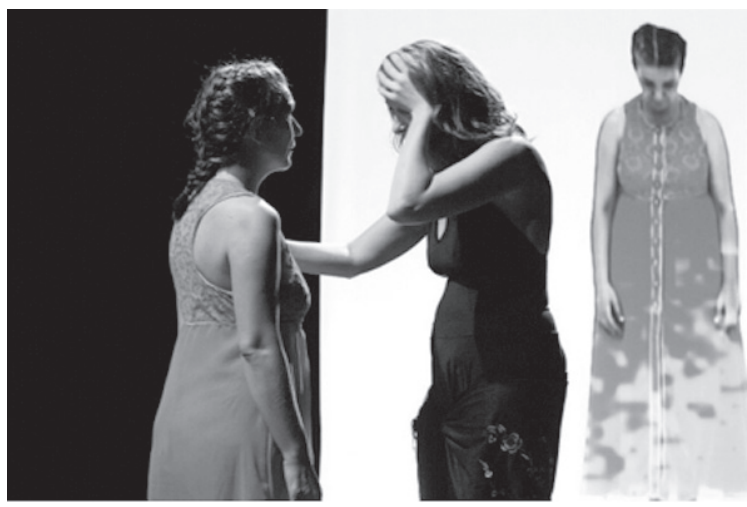

Figura 1. Es Inevitable. La primera obra de teatro de Casado Rubio. Fuente. Nadia Villanueva.

Su primera obra de teatro, como autor y director, fue Es Inevitable. Se estrenó en el Teatro La Carbonera en marzo de 2009 y realizó dos temporadas consecutivas de nueve meses ininterrumpidos. Ya en esta obra Casado Rubio puso en juego la intermedialidad al atravesar el lenguaje teatral con elementos provenientes de otros soportes como la plástica, el cine, y los recursos multimedia. A su vez, ya desde este inicio tan genuino, retomaba tópicos clásicos del teatro español y recursos teatrales de las renovaciones escénicas del siglo XX. La obra partía de una imagen muy concreta: una mujer llorando ante un ataúd, así se iniciaba el relato propuesto en el escenario. Nos explicó en la entrevista antes citada que es una imagen que viene de un clásico español (Miguel Delibes): "Para mí el dolor era eso: una mujer que llora velando el cajón. Para mí no había mayor dolor que ese, y a partir de eso vino la obra”. Esto mismo analizó Teresa Gatto cuando infirió el hipotexto que se presentaba en la obra (Cinco horas con Mario de Delibes) y señaló sobre el mismo que: “(...) tuvo gran recepción en los años 60 en España, utiliza el recurso del velatorio para que la viuda del fallecido repase no sólo la historia de ese amor, sino la opresión del régimen de 
Franco" (Gatto 2009, p. 3). Aquí, no sólo traemos esta imagen para ir a uno de los núcleos de la primera obra del autor sino para entender sus procesos creativos ya que es en función a una imagen creadora desde donde, según Casado Rubio, nace el impulso de su escritura. Desde el papel pasa a la escena teatral atravesada por todos los soportes que el autor y director mamó en su formación. En la entrevista que mantuvimos lo explicó diciendo:

Yo considero que lo importante es tener un buen guión, una buena historia. La historia estuvo como seis meses en mi cabeza, y luego, en un mes me senté y la escribí de corrido. Yo no tardo mucho en escribir porque tengo profesión, llevo muchos años escribiendo. Y no es que decidí "voy a utilizar video", sino que al escribir me salió contar así de esa manera, porque todo eran imágenes para mí y de hecho la obra partía de una imagen muy concreta (...) (Casado Rubio en Lozano, 2011).

Así, vemos que su discurso sobre su propio quehacer va dando mucha cuenta de su concepción del arte escénico. Tanto para el cine como para el arte teatral considera que el germen debe estar dado por un guión previo. Lejos de la improvisación o las creaciones colectivas, por ejemplo, su visión es que una buena historia construida mediante un relato escrito con estilo es el basamento capital. Esta certeza que tiene no lo rigidiza ni lo hace intolerante en los procesos de ensayos. Muy por el contrario el acercamiento al teatro hizo que aprendiera muchas cosas del oficio de la dirección escénica, entre ellas, que una vez estrenada la obra pasa a ser de los actores, o que un actor/actriz puede darle una nueva mirada a su escritura obligándolo a reconocer excesos, errores o mejoras. De modo que todo el talento que este autor tiene se ve potenciado por su capacidad de trabajo en grupo a la hora de dirigir sus propios materiales.

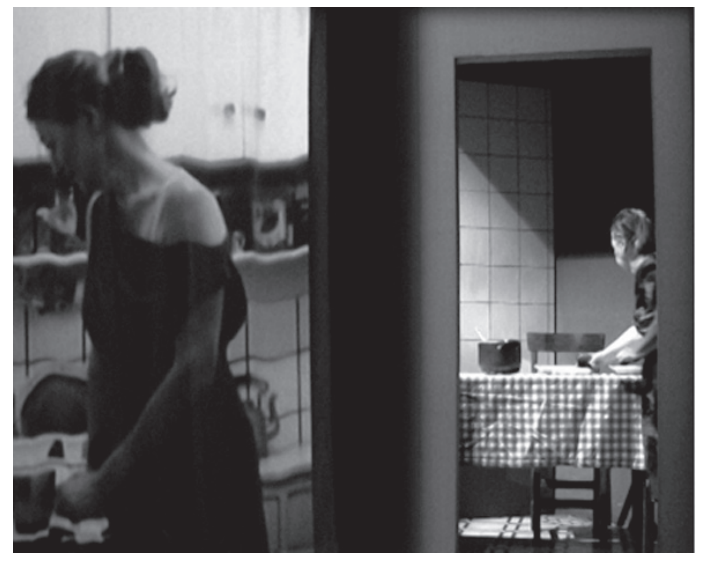

Figura 2. Se alquila... A partir de improvisaciones se modificaron las escenas. Fuente. Juan Borraspardo. 
Se alquila... se ensayó durante cinco meses, de tres a cuatro veces por semana. Los ensayos tenían una duración de tres o cuatro horas. Y, aparte, había ensayos de escenas puntuales o ensayo del actor con la coreógrafa. Es inevitable se ensayó a lo largo de siete meses pero, a diferencia de lo que sucedió en el proceso de la segunda obra no hubo tanto espacio para la improvisación. Las improvisaciones en Se alquila... fueron con el objetivo de generar vínculos: hijo-madre, abuela-nieto y madre-hija. En un momento posterior se encararon las escenas. Y, a partir de lo que se generó en las improvisaciones las escenas previamente escritas se alargaron y Casado Rubio escribió textos nuevos especialmente para el actor que antes tenía un personaje con menor desarrollo.

Con una experiencia cinematográfica en Argentina pudo comprobar, por vez primera, algunas cuestiones prácticas vinculadas a la dirección actoral. Cuando escribió y dirigió el mediometraje "Al Borde" (material que él describe como una comedia española sobre la mujer argentina) lo abordó desde la concepción de un guión de hierro donde las actrices no podían salirse un milímetro ni del texto ni de las acciones propuestas. Si bien fue una experiencia cuyo resultado lo dejó muy conforme artística y profesionalmente ${ }^{2}$, hoy -a la distancia-, puede reflexionar que ese modo de trabajo llevó a que las actuaciones resultasen rígidas. Así capitalizó esa experiencia y ya en la dirección de actrices que realizó en Es Inevitable logró estar permeable a lo que sucedía en la escena más que a su propio imaginario sobre lo que debería suceder.

De modo que se puede observar que el carácter intermedial de su teatro se comprende y que porta una formación sólida en técnicas cinematográficas que a la hora de tener que resolver problemas vinculados a las artes escénicas le permiten pensar la teatralidad con otra cabeza. Y defiende su lugar en el teatro independiente porteño afirmando: "Para mí el lugar del teatro es un lugar de experimentación" Si bien comprende que hacer teatro independiente significa manejar recursos de producción escasos (que hacen por ejemplo que un video pueda "colgarse") lo abraza como actividad porque le permite estar activo experimentando sin limitaciones. Y si bien su quehacer teatral parece haber echado unas profundas raíces que difícilmente lo alejen del mismo, su objetivo principal es desarrollarse como cineasta. Actualmente está trabajando en la preproducción de su primer largometraje que se filmará a finales de 2011 en Buenos Aires en coproducción con España. ${ }^{3}$ Pero esta fase más cinematográfica no carece de lindes teatrales puesto que la actriz del mediometraje fue Mariela Asensio, reconocida intérprete y directora del teatro independiente de Buenos Aires. De hecho será con ella con quien podrá también otra faceta de la mixtura de lenguajes en el teatro diseñando los materiales audiovisuales de las obras $\mathrm{Cru}$ do, Mundo Amapola, y Mother dirigidas por la actriz. En esta misma línea trabajó también como realizador y creador audiovisual en varios proyectos teatrales dirigidos por José María Muscari: Laboratorio Político; Auténtico; y El Anatomista. El vínculo con Muscari se dio a partir de Crudo, la obra en la que José María actuó dirigido por Asensio. En este tipo de trabajos donde no dirige ni escribe, sí realiza una propuesta visual creativa para el teatro que se le propone. Además de un interés económico, lo mueven, para hacerlos, profundas indagaciones artísticas.

Si bien trabaja como creador audiovisual para otros teatristas se diferencia de ellos ya que considera que muchas veces el video en teatro se usa sólo para ilustrar o como separador. 
Por el contrario, en sus dos obras ocupaba un lugar central. Sobre el cine en su teatro reflexiona: "quiero que cuente la historia, que genere un clima. A mí me sirve para contar". Su texto para la escena ya posee una propuesta clara de luz y escribe con música. Como ejemplo traemos dos acotaciones de Se alquila con una condición: "Se escuchan los sonidos de una estación central de tren. La casa se transforma en una estación de tren gracias a la iluminación y al sonido" ; y, "Un contraluz delinea su cuerpo desnudo a través de la cortina de baño". Y esto no se escenifica sólo en proyecciones planas a una pantalla sino que las proyecciones son parte de la iluminación del espacio escénico, de la escenografía, de los y las intérpretes, etc. La luz del proyector es parte central de la puesta de luces de cada obra. De igual modo la luz es parte central del trabajo con el desnudo que hace en $\mathrm{Se}$ alquila...Por todo este preciso trabajo de la luz en el espacio hay condiciones materiales que necesita para poder desarrollar su teatro en esta línea. Obviamente una sala con el suficiente equipo técnico-lumínico, pero también con ciertas características de visionado. Ese es uno de los motivos centrales por lo que sigue eligiendo la sala de La Carbonera ya que le brinda, a diferencia de la mayor parte de las salas actuales del teatro independiente en Buenos Aires, un espacio panorámico que, además, tiene profundidad. Estas dos características los convierten, según el propio director, en el espacio ideal para las puestas en escena que sueña. Y sumado esto, claro, un factor humano de quienes integran el equipo de trabajo de la sala.

En marzo de 2011 estrenó, también en La Carbonera, su segunda obra como autor y director llamada Se Alquila, con una condición. Si la opera prima de este dramaturgo partió de la imagen de esa mujer que llora ahora, en Se alquila... el puntapié inicial fue la imagen de una mujer mayor bañándose que es ayudada por su hija a salir de la bañadera. Como señalábamos, Casado Rubio cree firmemente en que todo se origina desde una imagen; y que la misma impone un tema. Así, sobre la obra anterior describía Gatto:

En Es Inevitable, la muerte dispara las reflexiones sobre el ocultamiento y la discriminación a la que son sometidas las parejas homosexuales. El monólogo cobra aquí una función polifónica, ya que narra las voces de los que segregan la unión. Ellos llegarán a las exequias y reprobarán y tal vez desalojarán a la viuda. El mar, que desde España trajo al amor que ha muerto, traerá también a aquellos que, tal vez horrorizados, terminen de destruir lo que queda de la familia (Gatto, 2009, p. 3).

Esta obra polemizaba en teatro un tema que socialmente, todavía, no tenía un debate profundo. Curioso fue que años después, cuando seguí en funciones, la obra entró en diálogo con todo el debate que se dio en la sociedad argentina en torno a sanción de la Ley de Matrimonio Igualitario. Pero todo este núcleo temático no escapaba al desarrollo intermedial de la escena. En Es inevitable los videos empezaban a esbozar en la cabeza de cada espectador/a la posibilidad de que la persona muerta llorada por la mujer (Estela Garelli) al principio era, también, una mujer (Patrizia Alonso) y no un hombre (como la mirada heteronormativa tendería a decodificar). De modo que aquel hipotexto de Delibes se resemantizaba con el llanto de una mujer a su pareja, otra mujer. 


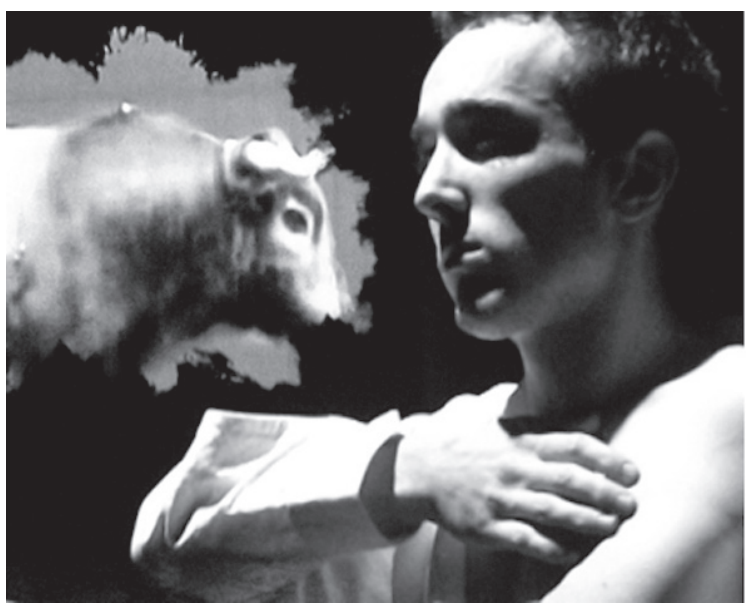

Figura 3. Se alquila... Videos e intermedialidad. Fuente. Juan Borraspardo.

Si bien, como dijimos, la imagen creadora de la bañera fue la que dio origen a la segunda propuesta, no es menor el dato que ambas obras comenzaban de un modo idéntico. Si en la primera la mujer lloraba ante un ataúd, en la primera escena de en Se alquila... Amador y Lucía lloran a Ramona (Chela Cardalda) que yace sobre una mesa. Claro que en breve comprobamos que era un juego. $\mathrm{O}$ sea que lo que su opera prima se mostraba como tragedia en su segunda propuesta se escenifica como comedia. Con este gesto autotextual Casado Rubio dialoga con su propio desarrollo artístico.

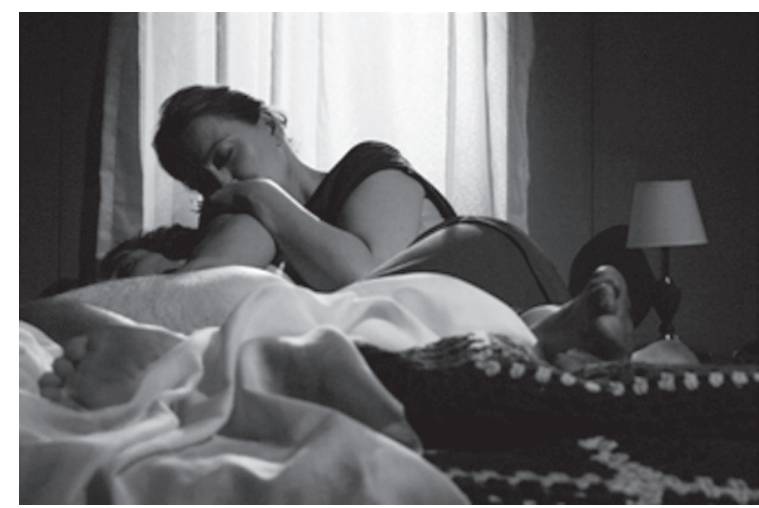

Figura 4. Se alquila... Tópico vinculado con la familia. Fuente. Juan Borraspardo. 
Una relación madre-hija en la bañera impone en el tema de Se Alquila, con una condición. Tópico vinculado con la familia pero trasvasado por el imaginario del autor. De modo que no será una obra de familia tradicional ni otra con esa tendencia de mostrar "familias disfuncionales" (que tanta productividad tuvo en la escena porteña de las últimas décadas). Sino que la obra propone meter un aguijón en la transmisión cultural de los lazos familiares, en la construcción de vínculos reales a partir de lazos ficticios. O sea tanto la imagen creadora de una obra como de la otra son muy concretas pero "comunes". Lo genial es la potencia del despliegue de las mismas que pudo lograr Casado Rubio. Los personajes de Lucía y Amador viven en la casa de Ramona no porque paguen con dinero su estancia sino porque son actores de la ficción que armó la dueña de casa para luchar contra su soledad, para luchar, como diría Lorca, "con esos terribles desconchados de las paredes". El personaje de la mujer mayor habilita a una propuesta lúdico-vivencial de actuar dentro de su casa "como si" fueran una familia a cambio de habitarla.

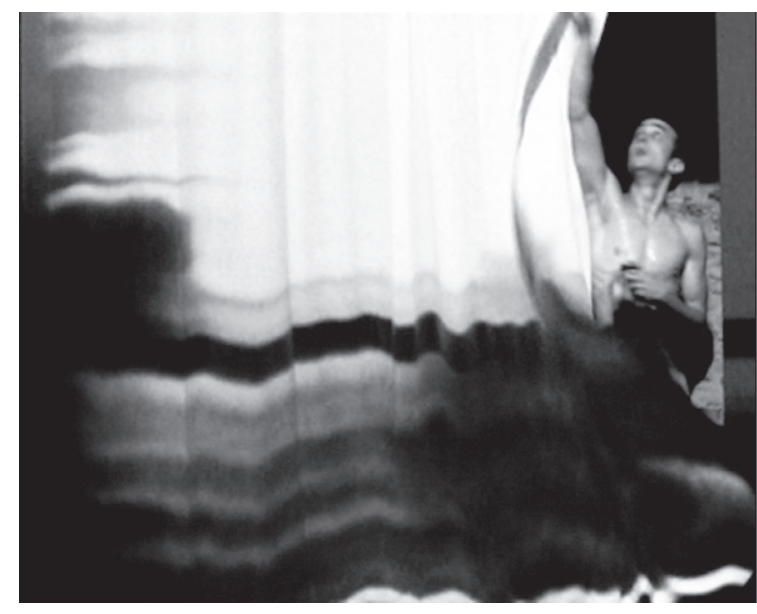

Figura 5. Se alquila... Un viaje lúdico. Fuente. Juan Borraspardo.

Y porque todo esto se tematiza no sólo como contenido sino como forma en Se alquila... es que Casado Rubio puede inventar un viaje lúdico donde la historia que se cuenta va y viene en el tiempo porque no apunta al entendimiento sino al tránsito por el mundo del relato que nos acerca. Ya lo advierte en el programa de mano de la obra: "Te propongo dejar de pensar y que te dejes llevar.", "No importa de dónde venís, lo importante es que viniste". Y en este juego que tematiza una ficción dentro de la ficción se posibilita que, por ejemplo, sea tan fuerte el vínculo imaginario de madre-hijo que actúan Lucía y Amador que hace que muchas y muchos espectadores crean de verdad que la atracción sexual que los mueve sea incestuosa. Aunque también es cierto que si la propuesta de la familia elegida y construida es lo que se propone el incesto también la atraviesa. 
Si en Es inevitable se observaba una mixtura de lenguajes que no se integraban de manera del todo armónica, logró en su segunda propuesta teatral una amalgama entre los soportes mucho más precisa. Ejemplo de ello es el uso en Se alquila... del recurso de la voz en off. En ella un relator (Rodolfo Valss) nos sumerge en la narración. Pero no cumple los roles tradicionales de este recurso sino que -una vez más- Casado Rubio lo interviene para que desestabilice la percepción normativizada del público. Así, por ejemplo, hay una escena en particular donde el personaje de Lucía (Estela Garelli) se pelea con esa voz que relata.

LUCÍA.- Yo no fui, vino él. Y no por mí. Él no me quiere. Yo lo sé. Ni me mira, ni se acordó de mí cuando me vio en la casa.

RELATOR.- Basta! Terminala.

LUCÍA.- Basta vos!

RELATOR.- Acá el único que cuenta soy yo. Hacemela fácil. Sí?

Lucía asiente con la cabeza.

Y sobre este particular nos ampliaba en la entrevista que: "tenía ganas de ir rebobinando la historia. Sí que hubo un procedimiento mucho más consciente de hacer cine en teatro. Es inevitable fue bastante intuitiva, escribí lo que quise, a la gente le gustó y a mí me gustó lo que quedó. Ahora quería hacer mi segunda obra. (...) Hubo una consciencia en mí de estructurarla de esa manera: por eso la voz en off." Y por eso también esta propuesta tan cinematográfica de los flashbacks y los flashfowards que pone ante los ojos del público en una serie de números discontinuados en el programa de mano pero hitchcockianamente quedan vedados a pesar de haber siempre estado ahí revelando el orden temporal de la historia que propone este relato.

Sumado a todo lo dicho resta agregar que hay una reiteración de recursos propiamente teatrales para dar cuenta del artificio puesto en marcha en ambas obras. En Es inevitable, por ejemplo, la hija de ambas mujeres (Lorena Viterbo) ingresa a escena desde el público luego de que su celular suene en la platea (generando una incomodidad en muchas personas del público). Y en Se alquila... es Amador (Emiliano Dionisi) quien desde la escena usa a las personas del público como ayudantes para obtener cigarrillos. Se utiliza el espacio destinado al ingreso del público y se lo ilumina. Por más realismo que la escena derrame Casado Rubio obliga en determinados momentos a que se tome distancia de lo narrado. Este sentido se radicaliza en la última obra para, como anticipamos, lograr que el entendimiento no sea lo que domine la percepción sino el juego propuesto. Así nos los confirmó en la entrevista cuando afirmaba: "quiero que el público esté implicado (...) A mí como espectador me gusta que me hagan pensar"

\section{Gesto queer y teatralidad}

Más arriba explicamos la imagen que dio pie a Se Alquila, con una condición y dijimos que esta obra propone aguijonear la construcción cultural de lazos familiares; que propone una reflexión a propósito de la construcción de vínculos reales a partir de lazos 
ficticios. Bien. Es aquí, señalamos nosotros, donde aparece lo que denominamos como el gesto queer de su dramaturgia. Si, como dice poéticamente Sejo Carrascosa, "queer es un punto de ternura ajeno a la economía heterosexual” (Carrascosa, 2005, p. 175) y, al mismo tiempo, queer son "los monstruos que aparecen por las grietas del urbanismo patriarcal” (Carrascosa, 2005, p. 175), la ambigüedad del término establece, al menos, una oposición a la claridad del mandato heteronormativo dominante en el mundo. Pero este mandato no sólo hace referencia a la pareja elegida desde el deseo y a la vivencia del amor entre dos personas como sería el caso de la primera obra, sino también a la posibilidad de concebir lazos otros a los que se atribuyen vínculos fuertes ligados a lo familiar a pesar de que lo sanguíneo no acompañe ni aparezca la figura del Padre, como sería en el caso de la segunda obra. Porque será en boca de el personaje de Amador, principalmente, que se tematizará esto en el conflicto de los personajes cuyo alquiler no tiene costo monetario, sino la propuesta lúdico-vivencial de actuar dentro de la casa de Ramona "como si" fueran una familia. Lucía en su rol de hija de Ramona y Madre de Amador; y Amador en su rol de nieto e hijo jugarán este juego. Así el personaje que interpreta Emiliano Dionisi puede cuestionarse: “¿Se puede sentir pena de algo que nunca pasó?”Y lo curioso es que está idea tematizada transforma en metateatrales algunos aspectos de la obra. Casi una reflexión sobre el propio quehacer de las actrices y los actores. ¿Se puede, mediante estímulos imaginarios, vivenciar experiencias reales? Esta pregunta que obsesionó a tantos pedagogos del arte escénico se problematiza en este contexto donde "la ficción" que se vive como real es la de "una familia". Y es un tópico con resonancias muy amplias a pesar de lo particular de su formulación. Puesto que puede abarcar tanto a una familia elegida (como esta que presenta la obra) tanto como a muchas otras realidades que ponen en crisis ese concepto "tradicional" de lo familiar transmitido por el orden patriarcal y heteronormativo. Reflexionará también Amador: "De dónde vienen los monstruos. Ni idea".

Entre las muchas concepciones de teatralidad que existen vamos a tomar aquí la de Gustavo Geirola para volver a pensar lo corporal en el ámbito del convivio teatral (Dubatti, 2003). Según Geirola, la teatralidad, que es social, instaura una guerra óptica donde un cuerpo en acción (el de quien actúa) debe dominar la mirada del otro (la de quien mira la escena). Un juego de seducción, donde el movimiento no es el único derivado energético sino algo más fundamental: el poder. Al menos es desde estas concepciones que esboza su reflexión sobre una semiótica de la teatralidad.

Para constituir la teatralidad como concepto podemos establecer, en un nivel estático, cuatro elementos básicos: cuerpo, mirada, tiempo y luz. En un nivel dinámico podemos adicionar la energía. (...) Alguien mira un cuerpo en movimiento (...) Se mira, pues, un cuerpo en acción; se mira por un sentido, no por su falta, ya que la mirada narrativiza"(Geirola, 1993, p. 28).

Este recorte que hace Geirola toma como un elemento fundamental los cuerpos de este convivio pero reduce el cuerpo del espectador a la mirada. Creemos que la percepción del espectador en su rol no se reduce a lo visual. Todos sus sentidos intervienen en ese juego de seducción. Es un encuentro de cuerpos, un convivio donde la totalidad del cuerpo del 
actor/performer/bailarín está al servicio de ser percibido por otro cuerpo, a quien tendrá que estimular constantemente para que la seducción continúe. ¿Qué mira quien mira teatro/danza/performance? ¿Qué ve en el cuerpo del intérprete/performer? ¿Qué fragmentos del cuerpo privilegia la escena? Si la corporalidad se construye socialmente, si no nos es dada o no es natural, si somos producto de la interacción con otros: ¿qué construcción de lo corporal, establece la relación de la escena con su espectador? Los cuerpos en escena como objetos de la mirada para otros cuerpos que miran, que ponen el cuerpo para mirar. Encuentro de cuerpos, encuentro de presencias. Energía. Reto de la carnalidad. Género lábil, género móvil.

Para la conceptualización que hemos abordado aquí, en la teatralidad se trata de dominar la mirada dado que existe "un campo agonal constituido como estrategia de dominación" (Geirola, 1993, p. 28). Agregamos que en el marco de lo que se define como convivio teatral, debemos concebir a los (por lo menos) dos cuerpos que se vinculan en ese encuentro como cuerpos vivos. Esos cuerpos están atravesados por una serie de construcciones sociales. Si ya no podemos concebir como naturales a una serie de normativas atribuidas a esas corporalidades normalizadas, creemos que se debe pensar una nueva forma de concebir el encuentro de los cuerpos. La mirada narrativiza, la ficción también, la sociedad también. Hay un relato previo a la escena: el relato acerca de nuestros cuerpos.

Existimos en un mar de relatos poderosos. Ellos son la condición de la racionalidad finita y de las historias de vida personales y colectivas. No hay camino fuera de los relatos. (...) Cambiar los relatos, en un sentido tanto semiótico como material, es una intervención modesta que merece la pena. (Haraway, 2004, p. 63).

Si modificamos los relatos, como invita Harraway: ¿qué nuevas modificaciones se producen en los demás relatos? ¿Y en nuestros cuerpos? ¿Cómo transformaremos nuestras conceptualizaciones para pensar la teatralidad?

\section{Palabras finales}

Volviendo a la conceptualización de intermedialidad que tomamos al principio podemos agregar una nueva ampliación a la misma.

La mediatización no debe ser considerada como el diablo absoluto, sino como uno de los componentes de las mediaciones entre los textos y los seres humanos, al lado de las estructuras, las formas, las retóricas, los juegos de palabras, las seducciones artesanales (¡mucho más eficaces, por lo demás!). El texto dramático es el punto de partida para otra teatralidad, una teatralización más sutil, una puesta en escena más móvil. La textualidad se abre a la intermedialidad y convierte la puesta en escena en el origen y la finalidad del sentido virtual y estético de las obras. (Pavis, 2001, p. 1) 
Y por su parte, en el artículo antes citado, Pinta concluye que el teatro:

(...) ofrece otra respuesta a esta lógica cultural. Pavis señala, igualmente, que la influencia del medio de comunicación sobre el texto y/o espectáculo pasa necesariamente por un cuerpo intermedio: en el aquí y ahora de la representación teatral surge el cuerpo del actor (que, a pesar de encontrarse sometido a la regularidad de la máquina, logra instalar su presencia evanescente, singular y con ella su voz, su palabra, su ritmo biológico) y también el cuerpo deseoso del espectador. Paisajes tecnológicos mediante, la experiencia estética entendida como conocimiento sensible, somático, se resiste a abandonar la escena cultural contemporánea y encuentra en el teatro algo de su dimensión vital. (Pinta, 2010, p. 12).

Así lo entiende Casado Rubio, creemos. Elige y confía en sus actrices y sus actores: la elección sucesiva de Patrizia Alonso para su mediometraje y para Es inevitable; la vinculación tan particular que logra con su protagonista Estela Garelli en sus dos propuestas teatrales; la elección de Chela Cardalda -actriz de refinada trayectoria artística-; la escucha hacia la creatividad de Emiliano Dionisi a quien le escribiera nuevos monólogos y ampliara escenas ${ }^{4}$ dan cuenta de su amor por los intérpretes. Dan cuenta de que no pone lo mediático por sobre lo humano -base indiscutible de toda teatralidad-. Casado Rubio entiende que el sitio de la mirada del espectador instaura una situación de visionado a partir y con el cuerpo de las actrices y los actores. Elige a las y los mejores intérpretes potenciando las multiplicaciones dramáticas a partir de recursos intermediales.

Dijimos al comienzo que reflexionar sobre la producción de Diego Casado Rubio era entender el discurrir audiovisual de la dramaturgia, las potencias plásticas de la representación teatral, el cine hecho cuerpo en convivio. Creemos que el concepto de intermedialidad nos ayudó a hacerlo. Las dos obras pensadas en este escrito dan cuenta que todo el atravesamiento de lo mediático se debe apoyar siempre en el cuerpo vivo de actrices y actores para que la teatralidad se instaure, y para que el público, cuerpo deseante compartiendo la escena, conserve ese motor de degustar la dimensión vital que todo teatro -que se precie de tal- siempre resguardará.

\section{Notas}

1. Entrevista a Diego Casado Rubio por Ezequiel Lozano realizada el 19 de mayo del 2011. La misma no fue publicada. Todas las citas del discurso de Casado Rubio refieren a la misma.

2. La película recorrió festivales nacionales e internacionales.

3. Anteriormente, también, su guión Flamenco Bar fue premiado con el IV Programa de Desarrollo de Proyectos Cinematográficos Iberoamericanos de la Fundación Carolina y la Casa de América de Madrid.

4. El personaje de Amador era un bailaor Flamenco que se fue modificando a través de los ensayos a partir del trabajo con Emiliano Dionisi. 


\section{Referencias Bibliográficas}

Carrascosa, S. (2005). ¿Qué es queer? En, Córdoba D., Sáez, J. y Vidarte, P. Teoría Queer. Políticas Bolleras, Maricas, Trans, Mestizas. Barcelona: Egales. Págs. 179-180.

Casado Rubio, D. Se alquila con una condición, mimeo.

Dubatti, J. (2003). El convivio teatral. Buenos Aires: Atuel.

Gatto, T. (2009, diciembre). El ineluctable dolor del amor en Es inevitable de Diego Casado Rubio. En, telondefondo. Revista de Teoría y Crítica Teatral. Año V, No 10. [On Line]. Disponible en: www.telondefondo.org

Geirola, G. (1993). Bases para una semiótica de la teatralidad: espacio, imagen y puesta en escena. En, Gestos No 15. Irvine: Universidad de California. Págs. 25-40

Haraway, D. (2004). Testigo_Modesto@,Segundo_Milenio: HombreHembra,_Conoce_Oncoratón. Barcelona: UOC.

Pavis, P. (2001, oct.-dic.) Escrituras dramáticas contemporáneas y nuevas tecnologías. En, Revista Conjunto, Casa de las Américas, $n^{\circ}$ 123. [On Line]. Disponible en: www.casa.cult. $\mathrm{cu} /$ publicaciones/revistaconjunto/123/pavis.htm

(1998). Del texto a la escena: un parto difícil. En, Teatro contemporáneo: imágenes y voces, Santiago: LOM Ediciones.

Pinta, M. F. (2010, julio). Escenarios intermediales. De los happenings a la web 2.0. En, te londefondo. Revista de teoría y Crítica Teatral, Año VI, No 11. [On Line]. Disponible en: www.telondefondo.org

\section{Fichas Técnicas}

\section{Se Alquila, con una condición}

Autor, director y creador audiovisual: Diego Casado Rubio

Actúan: Chela Cardalda (Ramona), Estela Garelli (Lucía) y Emiliano Dionisi (Amador)

Voz en off: Rodolfo Valss

Asistente de dirección y Productor ejecutivo: Juan Borraspardo

Escenografía Ariel Vaccaro

Vestuario Vessna Bebek

Realización de vestuario Nancy Murena

Iluminación Leandro Fretes y Jimmy James

Coreografía Fabiana Pouso

Música original, diseño y postproducción de sonido Diego Menge

Diseño y realización bañadera Nicolás Botte

Asistente general Marina Rosetti

Diseño de gráfica y web Diego Casado Rubio

Prensa Carolina Alfonso

Producida por EL PRINCIPITO PRODUCCIONES

www.sealquila.com.es 


\section{Es Inevitable}

Dramaturgia: Diego Casado Rubio

Actúan: Patrizia Alonso, Estela Garelli, Lorena Viterbo

Cantantes: Josefina Lamarre, Aline Meyer

Músicos: Carlos Agüero, Diego Menge

Maquillaje: Vessna Bebek

Diseño de vestuario: Vessna Bebek

Diseño de arte: Vessna Bebek

Diseño de luces: David Seldes/

Realización de estenografía: Cristian Veneciani

Realización de vestuario: Nancy Murena

Realización de dispositivos lumínicos: Pehuen Stordeur

Audiovisuales: Diego Casado Rubio

Sonido: Franco Caviglia, Diego Menge

Artista plástico: Trinidad Rubio

Fotografía: Tomás García Puente, Nadia Villanueva

Diseño web: Diego Casado Rubio

Diseño gráfico: Diego Casado Rubio

Asistencia de dirección: Juan Borraspardo

Producción ejecutiva: Juan Borraspardo, Óscar Casado

Coordinación de audio: Kinan Vibra

Coreografía: Daniel Bartra

Dirección: Diego Casado Rubio

Producción de El Principito Producciones (Argentina- España)

http://www.esinevitable.es

Summary: Understanding intermediality as integrating aesthetic concepts from different media into a new context -in this case staging- the purpose of this paper is to reflect about the artistic director Diego Casado Rubio from this approach. This multifaceted artist borned in Madrid, is a film and theater director dedicated to graphic design for theater, developing video projects and writing. In 2005 he moved to Buenos Aires where developed a vast theatrical production in different roles. Referring to his other work this article will focus on the analysis of two plays written and directed by Casado Rubio: It's inevitable and For rent, on one condition.

Keywords: film - drama - intermediality - queer - technology

Resumo: Entendendo a intermedialidade como a integração dos conceitos estéticos provenientes de meios de comunicação diferentes num contexto original -neste caso uma posta em cena- a pretensão deste escrito é pensar as propostas artísticas do diretor Diego Casado Rubio desde essa noção. Este madrilense, que além de diretor cinematográfico e 
teatral dedica-se ao design gráfico para teatro, ao desenvolvimento de projetos de vídeo e à escritura, radicou-se em Buenos Aires em 2005 desenvolvendo uma vasta produção teatral em diferentes roles. Fazendo referencia a seus outros lavores, este artigo analisará duas obras teatrais escritas e dirigidas por Casado Rubio: Es inevitável e Aluga-se, com uma condição.

Palavras chave: cinema - dramaturgia - intermedialidade - queer- tecnologia. 